\title{
Is internal thoracic artery resistant to reperfusion injury? Evaluation of the storage of free internal thoracic artery grafts
}

Gábor Veres, MD, PhD, ${ }^{a}$ Harald Schmidt, MD, ${ }^{a}$ Péter Hegedüs, MD, ${ }^{a}$ Sevil Korkmaz-Icöz, PhD, ${ }^{a}$ Tamás Radovits, MD, PhD, ${ }^{b}$ Sivakkanan Loganathan, MD, ${ }^{a}$ Paige Brlecic, MD, ${ }^{a}$ Shiliang Li, MD, Matthias Karck, MD, PhD, and Gábor Szabó, $\mathrm{MD}, \mathrm{PhD}^{\mathrm{a}}$

\section{ABSTRACT}

Objectives: The in situ internal thoracic artery (ITA) is recognized as the best conduit for coronary artery bypass surgery. The ITA-if it is used as an in situ graft-has a much higher late patency rate than any other arterial graft, including a free ITA graft. We sought to determine if the use of the ITA as an in situ/free graft and its storage in preservation solutions, have an effect on endothelial function.

Methods: The ITA was harvested as either a free or in situ graft in a porcine model. Free grafts were stored in different preservation solutions (saline, Custodiol and Tiprotec [both Köhler Chemie GmbH, Bensheim, Germany]). The ITA was anastomosed off pump to the left anterior descending artery (as in situ/free graft). Freshly harvested ITA served as a control. After 2 hours of reperfusion, the implanted grafts were harvested. The assessment of endothelial function, histopathological analysis, and gene expression were performed.

Results: Endothelial function and integrity were severely impaired after reperfusion in the free ITA groups, however, it was partially preserved in the Tiprotec group. Reperfusion injury resulted in increased nitro-oxidative stress, DNA breakage, vascular cell adhesion protein 1, intercellular adhesion molecule-1, and caspase- 3 scores, and a decreased endothelial nitric oxide synthase score in the free ITA groups. The in situ ITA graft showed no signs of injury. mRNA levels were significantly altered among the groups.

Conclusions: An early, severe endothelial dysfunction of the stored, free ITA as described, could be completely prevented by the use of an in situ ITA graft. Tiprotec might be a feasible option for storage of free arterial grafts during coronary artery bypass grafting. (J Thorac Cardiovasc Surg 2018;156:1460-9)

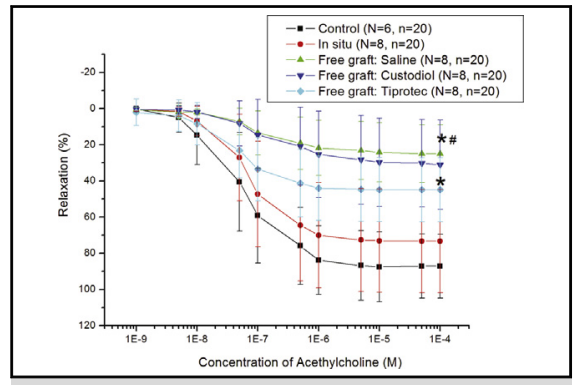

Vasomotor function of the internal thoracic artery.

\section{Central Message}

Early, severe endothelial dysfunction of the stored, ITA was described, which might play a negative role on patency rate. An in situ ITA graft showed no signs of injury.

\section{Perspective}

Our findings might have important implications in terms of graft survival and results after CABG, and they suggest that the implication of an in situ ITA over stored, free ITA graft might improve the beneficial effect of CABG with bilateral ITA grafting. Avoidance of storage solutions (saline/Custodiol) and preparation of the free arterial grafts similar to the in situ grafts should be considered.

See Editorial Commentary page 1470.
Over the past decade, many efforts have been made to improve coronary artery bypass grafting $(\mathrm{CABG})$ results. Interest has been focused on the extended application of

From the ${ }^{\mathrm{a}}$ Department of Cardiac Surgery, University of Heidelberg, Heidelberg, Germany; and ${ }^{\mathrm{b}}$ Heart and Vascular Center, Semmelweis University, Budapest, Hungary.

This work was supported by the Land Baden-Württemberg.

Received for publication Sept 13, 2017; revisions received April 27, 2018; accepted for publication May 2, 2018; available ahead of print July 6, 2018.

Address for reprints: Gábor Veres, MD, PhD, Department of Cardiac Surgery, University of Heidelberg, INF 326, 69120 Heidelberg, Germany (E-mail: gaborveres@ yahoo.com)

$0022-5223 / \$ 36.00$

Copyright (c) 2018 by The American Association for Thoracic Surgery

https://doi.org/10.1016/j.jtcvs.2018.05.079 arterial grafts. ${ }^{1}$ The internal thoracic artery (ITA) has the most favorable patency among conduits used for CABG. $^{2,3}$ The biological properties of the endothelium can protect the ITA from vasospasm, atherosclerosis, and neointimal hyperplasia (NIH). ${ }^{4}$ Moreover, compared with

- Scanning this $\mathrm{QR}$ code will take you to a procedural video. 


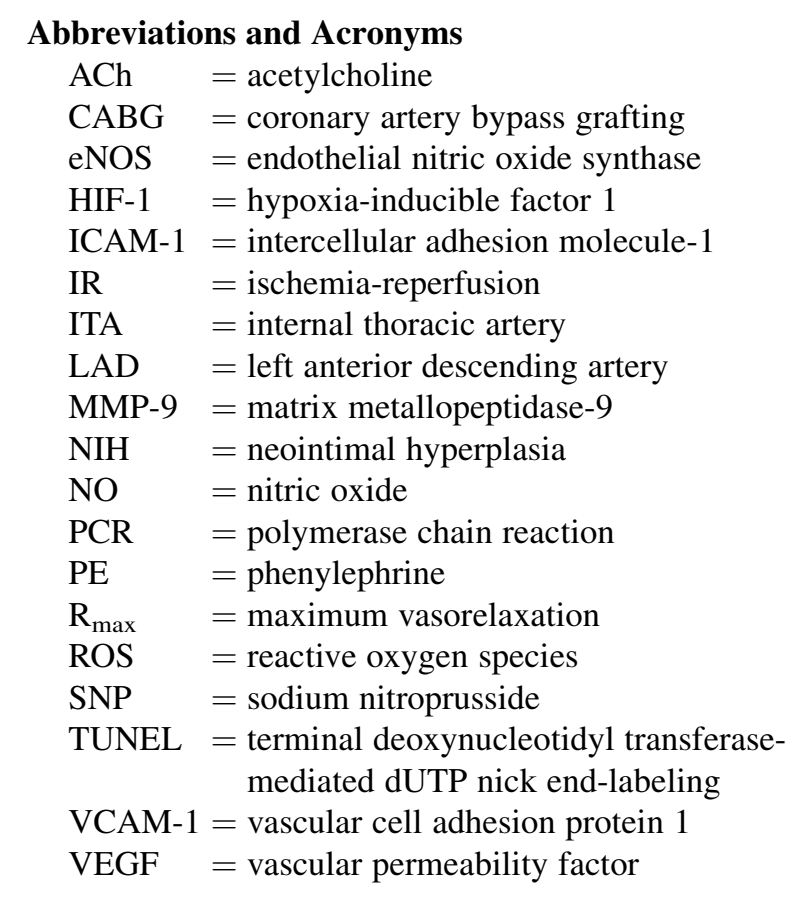

other conduits, it shows an increased production of nitric oxide (NO). ${ }^{4}$

After successful long-term results of single ITA grafting to the left anterior descending artery (LAD) ${ }^{5,6}$ many groups suggested that the use of both ITAs (free/in situ) would further improve the outcomes. ${ }^{7,8}$ This kind of expectation is on the basis of a hypothesis that in situ and free ITA grafts have similar biological characteristics such as contractility, vasorelaxation, endothelial function, and anatomical structure. However, the long-term results with free ITA grafts are controversial. ${ }^{9-11}$ Regarding the importance of an intact endothelial layer for graft patency, several different storage solutions for the preservation of free vascular grafts have been tested. However, these studies showed poor preservation capacity of routinely used preservation solutions (saline, Custodiol [Köhler Chemie GmbH, Bensheim, Germany]). A new preservation solution (Tiprotec [Köhler Chemie $\mathrm{GmbH}]$ ), which is an $\mathrm{N}$-acetyl-histidine buffered solution with iron chelators, dramatically improved endothelium preservation of free arterial grafts. ${ }^{12}$ For several years, antioxidant drugs that reduce reactive oxygen species (ROS) levels have been depicted as important therapeutic targets for the treatment of restenosis. ${ }^{13}$ To search for the possible differences among stored, free, and in situ ITA grafts, and to verify whether the endothelial function of the stored, free, and in situ ITA grafts were preserved after $\mathrm{CABG}$, we developed a new off-pump arterial revascularization model in pigs.

\section{METHODS}

\section{Animals}

Thirty-eight healthy pigs (25-35 kg) were used in this experiment. All procedures concerning animals were conformed to the Guide for the Care and Use of Laboratory Animals prepared by the Institute of Laboratory Animal Resources and published by the National Institutes of Health (Publication No 86-23, revised 1996). The investigations were reviewed and approved by the local Ethical Committee for Animal Experimentation. The pigs were randomly assigned to the 5 experimental groups (Figure 1): control $(n=6)$, ITA as a free graft (storage solution: saline; $n=8)$, ITA as a free graft (storage solution: Custodiol; $\mathrm{n}=8$ ), ITA as a free graft (storage solution: Tiprotec; $\mathrm{n}=8)$, or ITA as an in situ graft $(\mathrm{n}=8)$.

\section{Surgical Procedure}

Anesthetized pigs underwent an off pump procedure (Video 1). After median sternotomy and pericardiotomy, all left ITAs were harvested as free/in situ grafts.

In the in situ group, the ITA was harvested as a pedicle. After heparin was administered, the ITA was divided distally, the end was closed with a clip. The in situ ITA grafts were subjected to a 1-hour waiting period before the LAD anastomosis.

In the free ITA groups, the ITA was harvested as a pedicle graft. After heparin was administered, the ITA was divided distally and proximally,

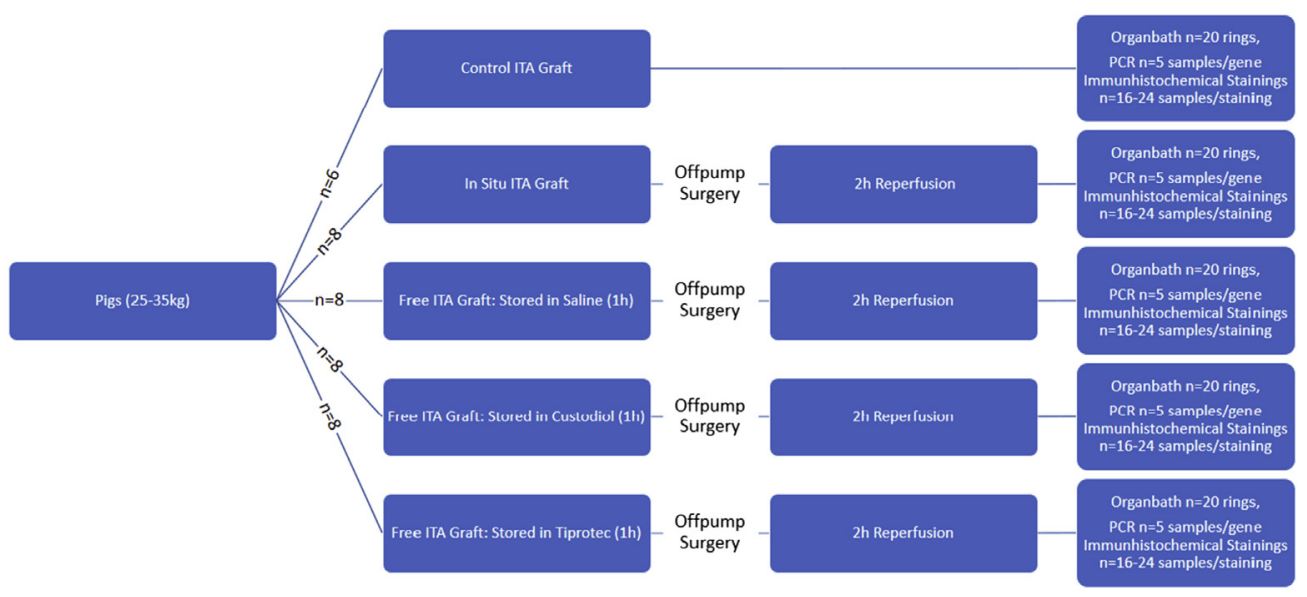

FIGURE 1. Groups and treatments. ITA, Internal thoracic artery; $P C R$, polymerase chain reaction. 


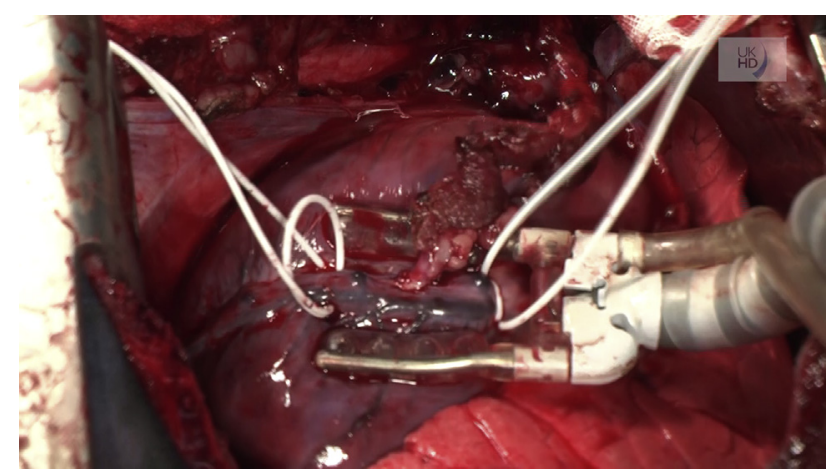

VIDEO 1. Evaluation of free and in situ internal thoracic artery grafts. Surgical procedure and results. Video available at: https://www.jtcvs.org/ article/S0022-5223(18)31509-5/fulltext.

then removed and subsequently flushed using cold preservation solution, thereafter it was stored for 1 hour. After 1 hour of ischemia, systemic anticoagulation was performed, and the ITA was anastomosed to the LAD and to the ascending aorta. In the in situ ITA group, the ITA was anastomosed to the LAD. The LAD was closed via ligature proximal to the anastomosis. Coronary blood flow was measured on implanted grafts with a perivascular ultrasonic flow probe (Transonic Systems Inc, Ithaca, NY) to control anastomoses' quality. Control group ITAs were freshly harvested.

After 2 hours of reperfusion (at the end of the experiments), ITA graft samples were taken and immediately immersed in fluid nitrogen $\left(-196^{\circ} \mathrm{C}\right)$ and stored frozen at $-80^{\circ} \mathrm{C}$ until the biochemical measurements were performed (nitrotyrosine, caspase-3, intercellular adhesion molecule-1 [ICAM-1], vascular cell adhesion protein 1 (VCAM-1), endothelial nitric oxide synthase (eNOS) stainings, and polymerase chain reaction [PCR]). Additionally, further ITA segments from each experimental group were fixed in paraformaldehyde solution (4\%) and embedded in paraffin. The 3-mm thick sections were placed on adhesive slides. These paraffin slides were used for terminal deoxynucleotidyl transferase-mediated deoxyuridine triphosphate nick end-labeling (TUNEL) and CD-31 staining.

\section{In Vitro Organ Bath Experiments}

After 2 hours of reperfusion, the implanted grafts were harvested and used for functional isometric tension measurements as described previously. ${ }^{12}$ At the beginning of each experiment, maximal contraction forces to $\mathrm{KCl}(80 \mathrm{mM})$ were determined and ITA rings were washed until the resting tension was again obtained. ITA preparations were preconstricted with an $\alpha$-adrenergic receptor agonist, phenylephrine $\left(\mathrm{PE} ; 10^{-6} \mathrm{M}\right)$, and relaxation responses were examined by adding cumulative concentrations of acetylcholine ( $\mathrm{ACh} ; 10^{-9}$ to $10^{-4} \mathrm{M}$ ). For testing the relaxation response of smooth muscle cells, sodium nitroprusside (SNP; $10^{-10}$ to $10^{-5} \mathrm{M}$ ) was used. Each specimen (ITA ring) was tested at 10 increasing concentration levels. Half-maximal response values were obtained from individual concentration response curves by fitting experimental data to a sigmoidal equation using Origin 7.0 (Microcal Software, Northampton, Mass). Contractile responses to PE are expressed as percent of the maximal contraction induced by $\mathrm{KCl}$. The sensitivity to vasorelaxants was assessed using the formula: $\mathrm{pD}_{2}=$ negative value for log half-maximal response $(M)$, vasorelaxation (and its maximum $\left[R_{\max }\right]$ ) is expressed as percent of the contraction induced by PE $\left(10^{-6} \mathrm{M}\right)$. Only 1 datum (the mean value of 3-4 aortic rings per animal) was used for the statistical analysis.

\section{TUNEL Reaction}

We performed TUNEL staining to detect DNA strand breaks as previously described. ${ }^{12}$ TUNEL-positive cell nuclei were counted by 2 blinded observers and thus, the mean value of the counted TUNEL-positive cell nuclei was used for the statistical analysis.
TABLE 1. Gene table

\begin{tabular}{|c|c|}
\hline Gene symbol & Alias \\
\hline$M M P 9$ & Matrix metallopeptidase 9 \\
\hline NOS3 & Endothelial nitric oxide synthase \\
\hline ICAM-1 & Intercellular adhesion molecule-1 \\
\hline SOD1 & Superoxide dismutase \\
\hline HIF $1 A$ & Hypoxia-inducible factor 1-alpha \\
\hline$I L 1 B 1$ & Interleukin-1 beta \\
\hline IL6 & Interleukin-6 \\
\hline$T N F$ & Tumor necrosis factor alpha \\
\hline VCAM-1 & Vascular cell adhesion protein 1 \\
\hline$B A X$ & Bcl-2-like protein 4 \\
\hline$B C L 2$ & B-cell lymphoma 2 \\
\hline$B C L 2 L 1$ & Bcl-2-Like Protein 1 \\
\hline CASP1 & Caspase-1 \\
\hline CASP3 & Caspase-3 \\
\hline IL10 & Interleukin-10 \\
\hline IL7 & Interleukin-7 \\
\hline PECAM1 & Platelet Endothelial Cell Adhesion Molecule \\
\hline SELPLG & P-selectin glycoprotein ligand 1 \\
\hline SERPINE1 & Plasminogen activator inhibitor 1 \\
\hline$V E G F A$ & Vascular permeability factor \\
\hline$V W F$ & Von Willebrand factor \\
\hline$C I D E B$ & $\begin{array}{l}\text { Cell-death-inducing DNA-fragmentation-factor-like } \\
\text { effector B }\end{array}$ \\
\hline CXCL8 & Alveolar macrophage chemotactic factor I \\
\hline$J U N$ & Proto-oncogene c-jun \\
\hline ILIB2 & Interleukin-1 beta \\
\hline CCNA1 & Cyclin A1 \\
\hline MYB & V-myb myeloblastosis viral oncogene homolog \\
\hline TROAP & Trophinin associated protein \\
\hline CAMK1 & Calcium/calmodulin-dependent protein kinase type 1 \\
\hline$D L G 4$ & Disks large homolog 4 \\
\hline GRIN2D & $\begin{array}{l}\text { Glutamate ionotropic receptor NMDA type subunit } \\
\text { 2D }\end{array}$ \\
\hline NOS1 & nNOS \\
\hline РPР $3 C A$ & Protein phosphatase 3 \\
\hline LOC100522128 & PRKAR1B \\
\hline PRKCA & Protein kinase $\mathrm{C}$ alpha \\
\hline NOS2 & Nitric oxide synthase \\
\hline DUOX1 & Dual oxidase 1 \\
\hline SELL & L-selectin \\
\hline GAPDH & Peptidyl-cysteine S-nitrosylase \\
\hline$B 2 M$ & Beta 2-microglobulin \\
\hline
\end{tabular}

Immunohistochemical Stainings (CD-31,

Nitrotyrosine, Caspase-3, eNOS, VCAM-1, ICAM-1)

To detect the loss of endothelial cells in the lumen of the ITA grafts, CD-31 staining was performed following the manufacturer's protocol 
(anti-CD31 porcine immunoglobulin G; Santa Cruz Biotechnology Inc, Heidelberg, Germany). According to the previously described methods, ${ }^{14}$ we performed immunohistochemical staining on ITA rings for nitrotyrosine, a marker of peroxynitrite-mediated damage, and for caspase-3, a marker of apoptotic injury. Immunohistological stainings for eNOS, ICAM-1, and VCAM-1 were performed using the immunoalkaline phosphatase technique described by Mason and colleagues. ${ }^{15}$ Results were performed by 2 or 3 blinded observers and thus, the mean value of these calculations was used for the statistical analysis.

\section{Gene Expression Analysis Using RT $^{2}$ Profiler PCR Arrays (Qiagen, Hilden, Germany)}

Using RT ${ }^{2}$ Profiler PCR Arrays, we determined the expression patterns of 38 genes (Table 1). Total RNA and microRNA were extracted from ITA graft samples with a miRNeasy Mini Kit (Qiagen, Hilden, Germany) and were reverse-transcribed into cDNA using the RT ${ }^{2}$ First Strand Kit, mixed with $\mathrm{RT}^{2}$ qPCR Master Mix, containing SYBR Green, according to manufacturer's instructions (Qiagen, Hilden, Germany). In this custom array, the following nonregulated genes (genes of interest) were used for normalization of the fold change expression data calculations: Glyceraldehyde-3-phosphate dehydrogenase, $\beta 2$-microglobulin.

\section{Chemical Reagents}

$\mathrm{PE}, \mathrm{ACh}$, and SNP were obtained from Sigma-Aldrich (Taufkirchen, Germany). Custodiol and Tiprotec were obtained from Köhler Chemie $\mathrm{GmbH}$.

\section{Statistical Analysis}

Statistical analysis was performed using SPSS Statistics 24 (IBM Corp, Armonk, NY). On the basis of our previous investigations, ${ }^{12,16}$ we calculated the Cohen $\mathrm{d}$ (in that case endothelium-dependent vasorelaxation: mean $1=90$, mean $2=25$, SD $1=5$, SD $2=16$, Cohen $\mathrm{d}=5$ ). We calculated with Cohen $\mathrm{d}=2.2$ in this study. Thus, in our present study, we needed 6 pigs per group. To improve the effect size, we used 8 pigs per group in our study. Data were tested for normal distribution with the Shapiro-Wilk test. In the case of vasorelaxation studies on ITA rings a repeated measurement analysis of variance was carried out with "vasorelaxant dose" as within-subject factor (repeated measures) and "graft storage type" as between-subject factor (independent groups). $P$ values for dose, group, and Dose $\times$ Group interaction were calculated. Bonferroni post hoc test for multiple comparisons were performed. Other results were compared using 1-way analysis of variance after pairwise $t$ test including Bonferroni correction $\left(\mathrm{R}_{\max }\right.$ to ACh, CD-31, nitrotyrosine, ICAM-1, TUNEL, eNOS) or Kruskal-Wallis test after pairwise $U$ test including Bonferroni correction (VCAM-1, caspase-3). Results are presented as mean $\pm \mathrm{SD}$. A value of $P<.05$ was considered indicative of significance after Bonferroni correction.

\section{RESULTS}

\section{Vasomotor Function}

After reperfusion, a significant impairment of endothelium-dependent vasorelaxation to ACh of ITA rings was shown in the free ITA groups compared with the control $(P<.05)$. In contrast, the in situ ITA had equivalent endothelium-dependent vasorelaxation compared with the control (Figure 2). Tiprotec improved the endotheliumdependent function of ITA rings compared with the saline group. Endothelial dysfunction was indicated by reduced maximal relaxation of ITA rings to $\mathrm{ACh}$ and a rightward shift of the concentration response curve compared with

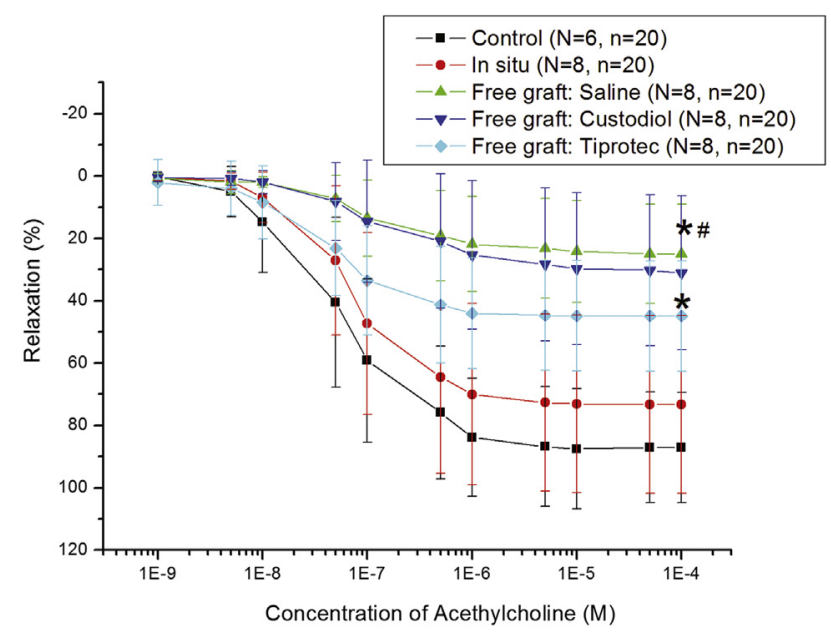

FIGURE 2. Vasomotor function of internal thoracic artery (ITA) grafts. Acetylcholine-induced endothelium-dependent vasorelaxation is shown after 2 hours of reperfusion. Values represent mean \pm SD. In the case of vasorelaxation studies on ITA rings a repeated measurement analysis of variance was carried out with "vasorelaxant dose" as within-subject factor (repeated measures) and "graft storage type" as between-subject factor (independent groups). Bonferroni post hoc tests for multiple comparisons were performed. Dose-effect $P$ value $<.0001$; group effect $P$ value $<.0001 ;$ dose + group effect $P$ value $=.0057$. Values of maximal relaxation were compared using 1-way analysis of variance after pairwise $t$ test including Bonferroni correction. $N$, Number of animals; $n$, number of rings; $1 E$, logarithm base. ${ }^{*} P<.05$ versus control ITA. $\# P<.05$ versus in situ ITA.

the control. There was no significant difference in $R_{\max }$ for endothelium-independent vasorelaxation of the ITA rings to SNP among the experimental groups. Contractile responses of ITA rings to $\mathrm{PE}\left(10^{-6} \mathrm{M}\right)$ are shown in Table 2 .

\section{Oxidative Stress and Apoptosis}

An increased density of TUNEL-positive nuclei indicates severe DNA fragmentation in the arterial wall (intima and media) in the experimental groups. Significantly increased DNA strand breaks (Figures 3 and 4) were observed throughout ITA groups, however TUNEL-positive cells in the in situ ITA and free ITA:Tiprotec group were significantly lower compared with the free ITA:saline and Custodiol groups.

Immunostaining for nitrotyrosine showed significantly enhanced immunoreactivity in the wall of free ITA grafts. The control and in situ ITA group showed decreased nitrotyrosine immunoreactivity. Preservation of the ITA in Tiprotec significantly reduced oxidative stress compared with the free ITA:saline group (Figures 3 and 4).

An increased density of caspase-3-positive cells indicated a severe apoptosis rate in the free ITA:saline and Custodiol groups. No significant changes were found in the vessel wall for caspase-3 staining in the in situ and free ITA: Tiprotec groups compared with the control (Figures 3 and 4). 


\section{eNOS Expression}

Immunostaining for eNOS showed significantly enhanced immunoreactivity in the wall of ITA rings of the control and in situ ITA groups. The eNOS score was significantly lower in the free ITA groups (Figure 4).

\section{Expression of Adhesion Molecules (CD-31, ICAM-1, VCAM-1)}

The inner walls of all ITA segments were covered with endothelium showing a positive CD-31 reaction. In the control group the endothelial surface showing a positive reaction for the CD-31 antigen (Figure 3) was estimated as $87 \pm 2 \%$, whereas in most free ITA vessels this rate was significantly lower $(63 \pm 6 \%$ in the saline group, $70 \pm 8 \%$ in the Custodiol group; $P<.05$ ). The CD-31 reaction was not reduced in the in situ ITA and free ITA: Tiprotec group compared with the control.

Immunohistochemical staining revealed high expression of VCAM-1 and ICAM-1 in the free ITA groups. Control ITA grafts barely expressed ICAM-1 and VCAM-1. Immunohistochemical scores from the semiquantitative evaluation were significantly lower in the in situ ITA group compared with the free ITA groups (Figure 4).

\section{Changes in Gene Expression}

We determined the expression patterns of 38 genes. The up- and downregulated gene expressions are shown in Figure 5.

\section{DISCUSSION}

In our experimental study, off-pump CABG was used to simulate the clinical conditions witnessed during arterial revascularisation. This allowed both the observation of reperfusion injury's early effect on the endothelium of an ITA graft, and the evaluation of the preservation solution's effect on the vascular function of the ITA graft.

\section{Pathomechanisms of Graft Injury}

In the current study, we showed, to our knowledge, for the first time, that the vasomotor function of a stored, free ITA graft preserved in routinely used preservation solutions (saline/Custodiol) was severely damaged during the early stage of reperfusion injury. The results of the present experiment are in good agreement with previous studies ${ }^{17}$ and our previous reports on endothelial dysfunction of arterial grafts, in which severe endothelial damage also occurred immediately after the initiation of reperfusion. ${ }^{12,16,18}$ Furthermore, the reported functional endothelial impairment might also correlate to clinical findings after CABG, when the early postoperative complications (vasospasm/occlusion of bypass graft) often occurred during the first 24 hours. ${ }^{19}$ An interesting new finding of our study is that the vasomotor function of the in situ ITA graft was similar to the control ITA group.

Ischemia followed by rapid reintroduction of molecular oxygen per se results in a burst of ROS during the first minutes of reperfusion. ${ }^{20}$ Activated leukocytes also generate a number of ROS. The luminal surface of blood vessels is the most exposed tissue to the deleterious effects of ROS, which lead to endothelial cell death. There is now good evidence supporting an elevated production of ROS' contribution to cell dysfunction/death via induction of oxidative damage to cell macromolecules. ${ }^{20}$ Peroxynitrite (highly reactive coupling product of NO and superoxide) was also shown to be an important mediator of tissue injury in ischemia-reperfusion (IR) injury. ${ }^{21}$ Our immunohistological study revealed marked nitrotyrosine staining in the free ITA groups, however, the in situ ITA graft was free from injury. Furthermore, the results of TUNEL and caspase- 3 staining showed marked damage of the endothelial structure in the free ITA groups as a consequence of increased oxidative stress and apoptosis in the endothelium. We also detected extensive endothelial cell death, measured by a lower CD-31 expression in the

TABLE 2. Values of $\mathrm{R}_{\max }(\%$ and $\mathrm{g})$ and $\mathrm{pD}_{2}$ to $\mathrm{ACh}$, to SNP, and contraction forces induced by PE $\left(10^{-6} \mathrm{M}\right)$ in ITA rings in control, in situ ITA, free ITA:saline, free ITA:Custodiol, and free ITA:Tiprotec groups

\begin{tabular}{|c|c|c|c|c|c|c|}
\hline & $\begin{array}{c}\text { Control } \\
(\mathbf{N}=\mathbf{6} ; \mathbf{n}=\mathbf{2 0})\end{array}$ & $\begin{array}{c}\text { In situ ITA } \\
(\mathbf{N}=\mathbf{8} ; \mathbf{n}=\mathbf{2 0})\end{array}$ & $\begin{array}{c}P \text { in situ } \\
\text { versus control }\end{array}$ & $\begin{array}{l}\text { Free ITA:saline } \\
(\mathbf{N}=\mathbf{8} ; \mathbf{n}=\mathbf{2 0})\end{array}$ & $\begin{array}{c}P \text { saline versus } \\
\text { control }\end{array}$ & $\begin{array}{l}P \text { saline versus } \\
\text { in situ }\end{array}$ \\
\hline $\mathrm{R}_{\max }$ to $\mathrm{ACh}, \%$ & $87 \pm 17$ & $73 \pm 28$ & 1.000 & $25 \pm 16^{*}, \dagger$ & $<.0001$ & $<.0001$ \\
\hline $\mathrm{pD}_{2}$ to $\mathrm{ACh}$ & $7.2 \pm 0.5$ & $7.1 \pm 0.4$ & 1.000 & $6.7 \pm 0.6^{*}$ & .036 & .001 \\
\hline $\mathrm{R}_{\max }$ to $\mathrm{SNP}, \%$ & $82 \pm 23$ & $84 \pm 22$ & 1.000 & $93 \pm 10$ & 1.000 & 1.000 \\
\hline $\mathrm{pD}_{2}$ to $\mathrm{SNP}$ & $4.9 \pm 1.1$ & $4.6 \pm 1.5$ & 1.000 & $5.0 \pm 1.0$ & 1.000 & 1.000 \\
\hline $\mathrm{PE}, \%$ of $\mathrm{KCl}$ & $56.9 \pm 13$ & $81.0 \pm 22 *$ & .024 & $102.6 \pm 20^{*}$ & $<.0001$ & .064 \\
\hline Maximal contraction to $\mathrm{KCl}, \mathrm{g}$ & $7.1 \pm 1.9$ & $4.1 \pm 1.8^{*}$ & $<.0001$ & $3.5 \pm 1.7 *$ & $<.0001$ & .295 \\
\hline Maximal contraction to PE, $g$ & $4.0 \pm 0.9$ & $3.1 \pm 1.0$ & 1.000 & $3.5 \pm 1.7$ & 1.000 & 1.000 \\
\hline Blood flow after 2-hour reperfusion, $\mathrm{mL} / \mathrm{min}$ & & $29 \pm 16$ & 1.000 & $30 \pm 14$ & 1.000 & 1.000 \\
\hline
\end{tabular}

Values are presented as mean \pm SD except where otherwise noted. Significant $P$ values are adjusted using Bonferroni correction for multiple tests. $\mathrm{n}=$ Number of rings; ITA, internal thoracic artery; $R_{\max }$, maximal vasorelaxation; $A C h$, acetylcholine; $p D_{2}$, negative value for $\log$ half-maximal response; $S N P$, sodium nitroprusside; $P E$, phenylephrine; $\mathrm{N}$, number of animals. $* P<.05$ versus control. $\dagger P<.05$ versus in situ graft. $\ddagger P<.05$ versus Custodiol. $\S P<.05$ versus saline. 
free ITA graft groups. Thus, endothelial integrity and function were also severely damaged in the free ITA groups. Interestingly, the vasomotor function and the integrity of the endothelial layer of the in situ ITA graft was free from damage.

Endothelial dysfunction is also defined as the decreased synthesis, release, and/or activity of endothelium-derived NO. Endothelial cell activation by proinflammatory cytokines could lead to endothelial dysfunction by inhibiting eNOS expression and decreasing NO bioavailability through the induction of ROS. It has also been shown that NO donors can prevent intimal hyperplasia in animal models, which is the main cause of restenosis. ${ }^{22}$ On the basis of these observations, we determined the eNOS content using immunohistochemistry, as well as by measuring eNOS expression. As shown in Figure 4, immunoreactivity of eNOS was significantly higher in the in situ ITA group compared with those of the free ITA groups, thus it might theoretically be an explanation of the impaired vasorelaxation of the stored, free ITA grafts. In accordance with our results, much of the data derived from studies of IR-induced vascular dysfunction are consistent with the role of NO in the changed endothelium-dependent responses. ${ }^{23}$

During the early phase of reperfusion, several adhesion molecules are upregulated. On a functional level, adhesion molecules (VCAM-1, ICAM-1) lead to the recruitment of leukocytes to the endothelium and their migration into the tissue. In the current study we reported an overexpression of ICAM-1 and VCAM-1 in the free ITA groups. This finding is consistent with previous results in different models of regional IR. ${ }^{24}$ Several studies showed an increased concentration of ICAM-1/VCAM-1 after leukocyte-mediated heart injury. ${ }^{25}$ The importance of ICAM-1 and VCAM-1 in neutrophil-mediated injury was also shown. ${ }^{26}$ This agrees with our findings; a significant upregulation of ICAM-1 and VCAM-1 was shown in the free ITA graft groups, however the expression remained low in the in situ ITA group. In accordance with immunohistological results, we also detected a higher mRNA expression of ICAM-1 and VCAM- 1 in the free ITA groups.

Furthermore, the mRNA expression of hypoxia-inducible factor 1 (HIF-1), vascular permeability factor (VEGF), and matrix metallopeptidase-9 (MMP-9) were upregulated after reperfusion. Bateman and colleagues ${ }^{27}$ reported that during hypoxia, HIF-1, on an mRNA level, was significantly elevated very rapidly in the first 2 hours, which was followed by the increased levels of target genes (for example VEGF). There is evidence that endothelial injury is a primary cause of NIH, which is the basic pathology of vascular disease. ${ }^{28}$ VEGF and MMP-9 have an important role directly in the progress of $\mathrm{NIH} .{ }^{29,30}$ Guo et al reported that MMP-9 expression is increased during the first 2 weeks after endothelial injury, and thus a higher expression level of MMP-9 later contributes to intimal hyperplasia. ${ }^{30}$ HIF-1 has also been reported to be involved in NIH after vascular injury. ${ }^{31}$

\section{Effect of Different Preservation Solutions on Endothelial Function}

The available methods of preservation of free vascular grafts have a deleterious effect on the endothelium. Experimental studies reported poor preservation capacity of Custodiol and saline solution. ${ }^{12,16,18}$ In accordance with the literature, we also showed that Custodiol and saline are not optimal preservation solutions for the storage of free ITA grafts, as we showed by a severely impaired vasomotor function and changed structure of the stored, free ITA graft.

It has previously been reported that ROS play an important role in NIH, which leads to restenosis. ${ }^{13}$ Antioxidant drugs that reduce ROS levels have been described as important therapeutic targets for the treatment of restenosis. ${ }^{13,32}$

TABLE 2. Continued

\begin{tabular}{|c|c|c|c|c|c|c|c|c|}
\hline $\begin{array}{l}\text { Free ITA:Custodiol } \\
\qquad(\mathbf{N}=\mathbf{8} ; \mathbf{n}=\mathbf{2 0})\end{array}$ & $\begin{array}{c}\text { Custodiol } \\
\text { versus } \\
\text { control }\end{array}$ & $\begin{array}{c}\text { Custodiol } \\
\text { versus } \\
\text { in situ }\end{array}$ & $\begin{array}{c}\text { Custodiol } \\
\text { versus saline }\end{array}$ & $\begin{array}{l}\text { Free ITA:Tiprotec } \\
\qquad(\mathbf{N}=\mathbf{8} ; \mathbf{n}=\mathbf{2 0})\end{array}$ & $\begin{array}{c}\text { Tiprotec versus } \\
\text { control } \\
\end{array}$ & $\begin{array}{c}\text { Tiprotec } \\
\text { versus in situ }\end{array}$ & $\begin{array}{c}\text { Tiprotec } \\
\text { versus saline }\end{array}$ & $\begin{array}{c}\text { Tiprotec } \\
\text { versus } \\
\text { custodio }\end{array}$ \\
\hline $32 \pm 24^{*}, \dagger$ & $<0.0001$ & 0.001 & 1.000 & $45 \pm 18^{*}, \dagger$ & 0.002 & 0.036 & 0.328 & 1.000 \\
\hline $6.7 \pm 0.6^{*}, \dagger$ & 0.009 & $<0.0001$ & 1.000 & $7.3 \pm 0.4 \ddagger \S$ & 1.000 & 1.000 & 0.001 & 0.0001 \\
\hline $81 \pm 22$ & 1.000 & 1.000 & 1.000 & $84 \pm 16$ & 1.000 & 1.000 & 1.000 & 1.000 \\
\hline $4.4 \pm 0.8^{*}$ & 0.004 & 1.000 & 0.083 & $4.8 \pm 0.9$ & 1.000 & 1.000 & 1.000 & 0.838 \\
\hline $109.2 \pm 39^{*}, \dagger$ & $<0.0001$ & 0.019 & 0.814 & $66.8 \pm 19 \ddagger, \S$ & 0.170 & 0.601 & $<0.0001$ & $<0.0001$ \\
\hline $3.4 \pm 1.0^{*}$ & $<0.0001$ & 0.093 & 0.555 & $5.5 \pm 1.7^{*}, \uparrow, \S$ & $<0.0001$ & 0.147 & 0.003 & $<0.0001$ \\
\hline $3.6 \pm 0.9$ & 1.000 & 1.000 & 1.000 & $3.6 \pm .0 .9$ & 1.000 & 1.000 & 1.000 & 1.000 \\
\hline $29 \pm 11$ & 1.000 & 1.000 & 1.000 & $27 \pm 7$ & 1.000 & 1.000 & 1.000 & 1.000 \\
\hline
\end{tabular}



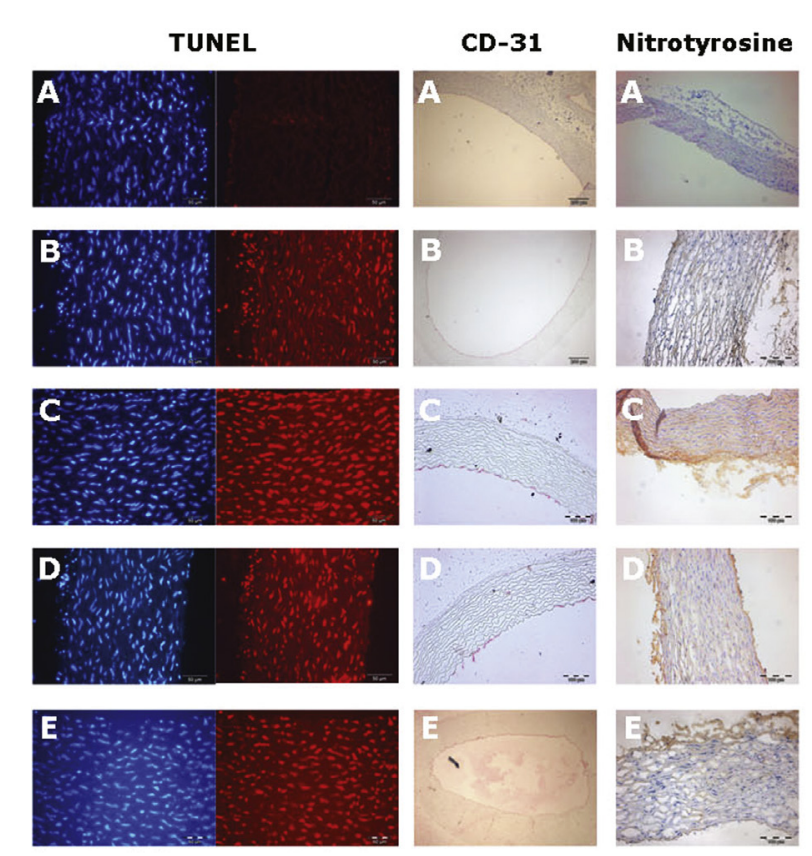
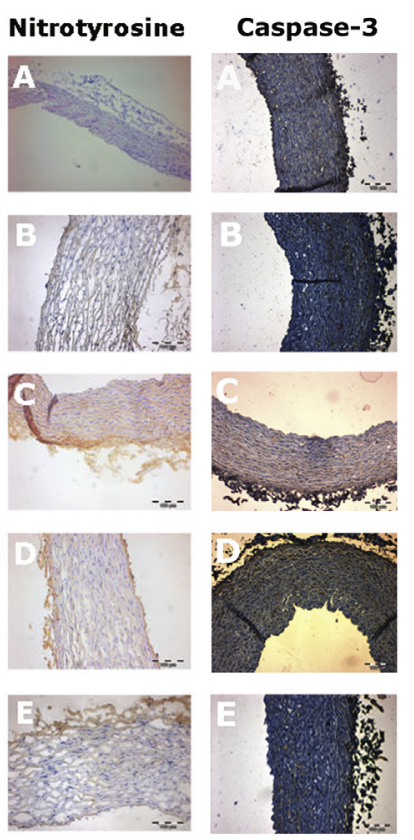
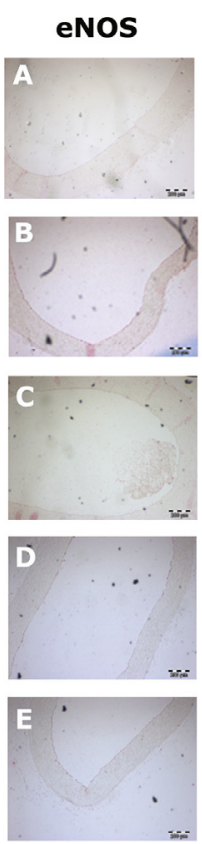

VCAM-1
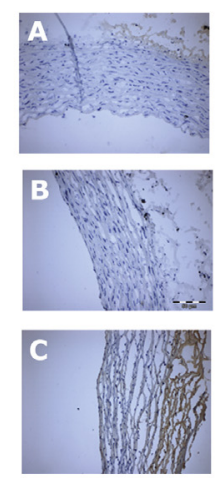
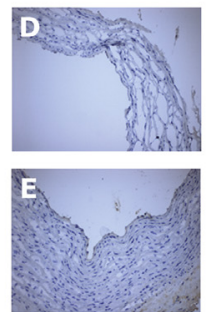

ICAM-1
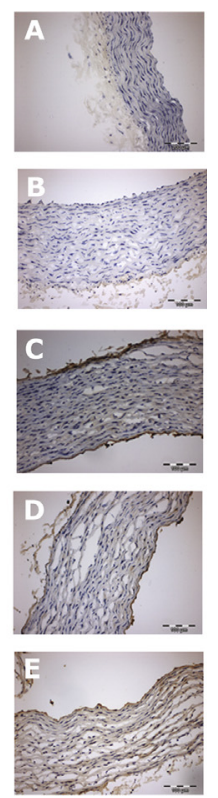

FIGURE 3. Representative photomicrographs of immunohistochemical stainings for terminal deoxynucleotidyl transferase-mediated dUTP nick end-labeling (TUNEL), CD-31, nitrotyrosine, caspase-3, eNOS, VCAM-1, and ICAM-1. Groups are indicated by (A) for control, (B) for in situ graft, (C) for free graft:saline, (D) for free graft:Custodiol, and (E) for free graft:Tiprotec. eNOS, Endothelial nitric oxide synthase; VCAM-1, vascular cell adhesion protein 1; ICAM-1, intercellular adhesion molecule-1.

On the basis of novel insights in cell/tissue injury during IR, a new preservation solution (Tiprotec) was developed. Tiprotec was modified in 4 important points to enhance the protective capacity of Custodiol solution: (1) addition of iron chelators to reduce iron-dependent injury, (2) partial substitution of histidine by $\mathrm{N}$ - $\alpha$-acetyl-L-histidine to inhibit
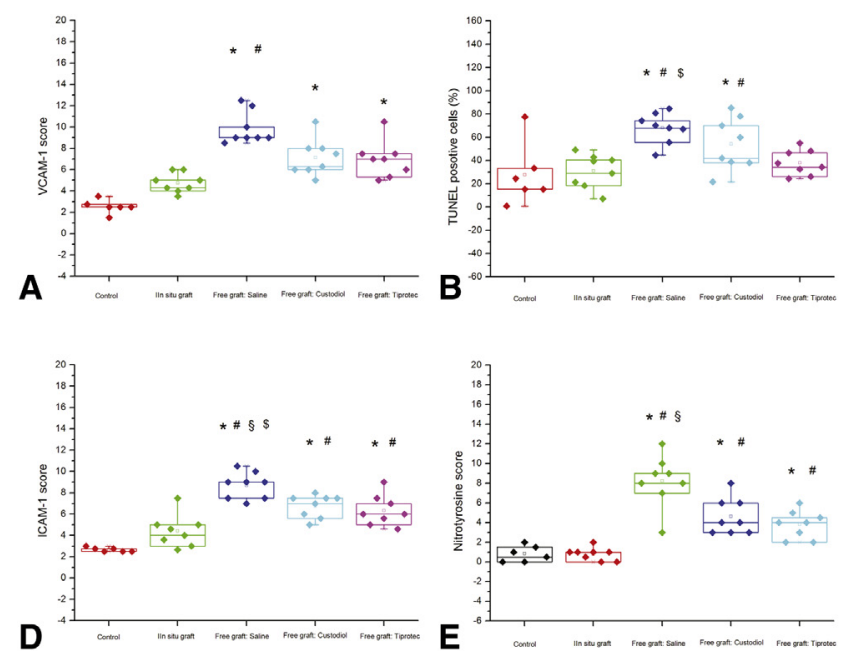
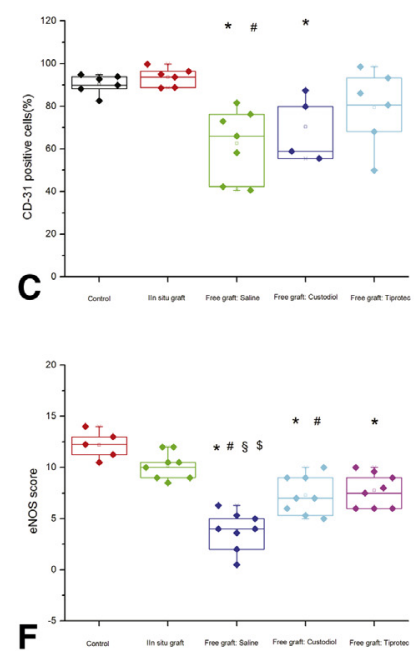

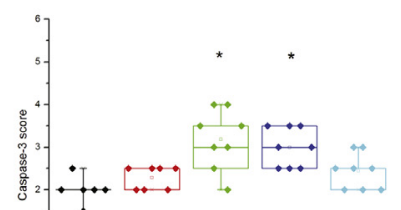

FIGURE 4. Semiquantitative scoring of immunohistochemical stainings for terminal deoxynucleotidyl transferase-mediated dUTP nick end-labeling (TUNEL), nitrotyrosine, caspase-3, vascular cell adhesion protein 1 (VCAM-1), and intercellular adhesion molecule-1 (ICAM-1); $\mathrm{N}=6$ animals, $\mathrm{n}=12$ for control, and $\mathrm{N}=8$ animals, $\mathrm{n}=16$ samples for other groups; $\mathrm{CD}-31(\mathrm{~N}=6$ animals, $\mathrm{n}=12$ samples), and eNOS ( $\mathrm{N}=6$ animals, $\mathrm{n}=18$ for control and $\mathrm{N}=8$ animals, $\mathrm{n}=24$ samples for other groups). Individual points in each group overlay box plot. The box defines the 25 th to 75 th interquartile range and median (line) and mean (empty square) values are shown within the box. Results were compared using 1-way analysis of variance after pairwise $t$ test including Bonferroni correction (CD-31, nitrotyrosine, ICAM-1, TUNEL, eNOS) and Kruskal-Wallis test after pairwise $U$ test including Bonferroni correction (VCAM-1, caspase-3). Global statistical results: caspase-3 $P=.002$; CD-31 $P=.001$, eNOS $P<.0001$, ICAM-1 $P<.0001$, VCAM-1 $P<.0001$, nitrotyrosine $P<.0001$, TUNEL $P=.0004$. ${ }^{*} P<.05$ versus control ITA; $\# P<.05$ versus in situ ITA; $\S P<.05$ versus free ITA:Custodiol; $\$ P<.05$ versus free ITA:Tiprotec. $e N O S$, Endothelial nitric oxide synthase. 
Scatter Plot: Control vs. In situ ITA

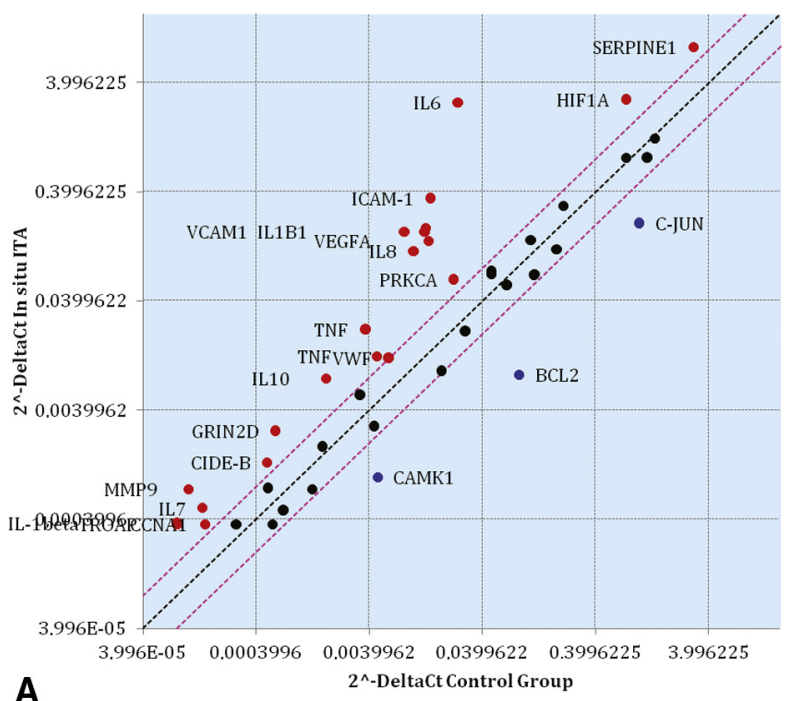

Scatter Plot: Control vs. Free ITA:Custodiol

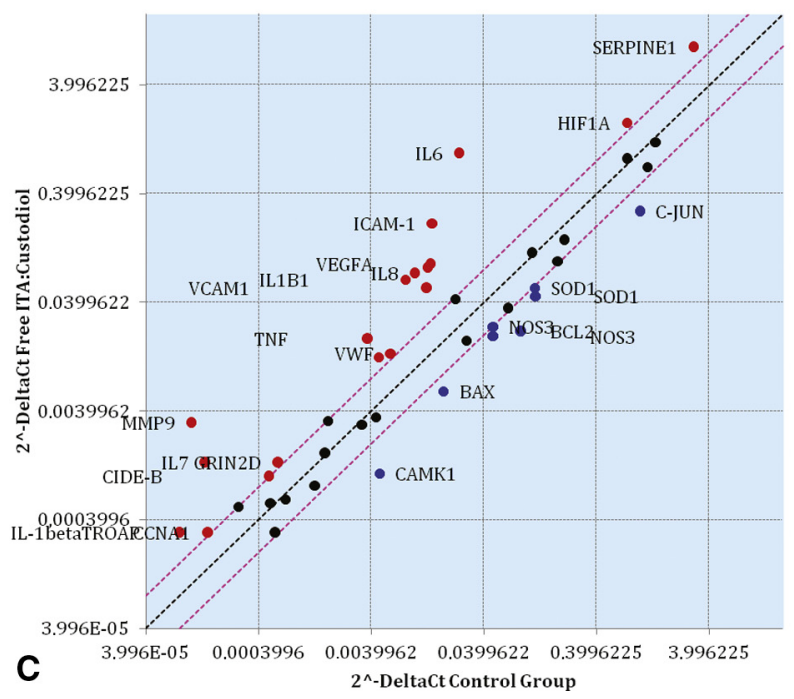

Scatter Plot: Control vs. Free ITA:Saline

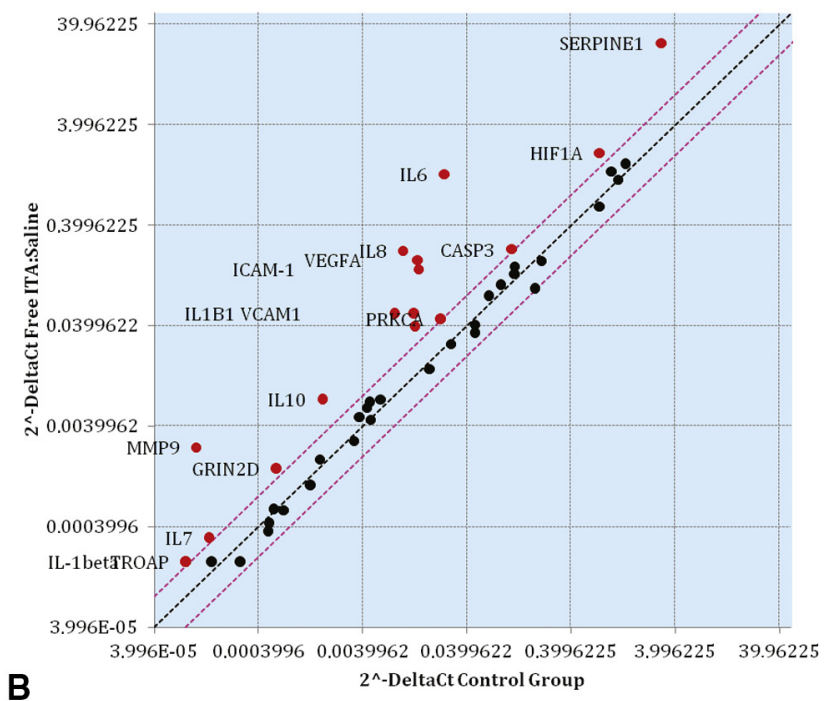

Scatter Plot: Control vs. Free ITA:Tiprotec

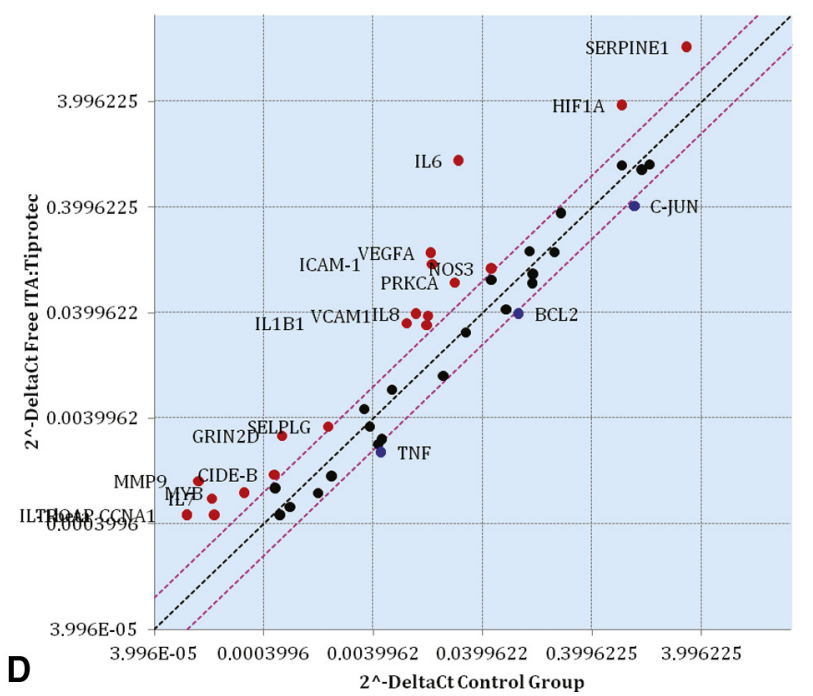

FIGURE 5. Up- and downregulated genes. A, Control ITA versus in situ ITA (scatter plot). B, Control ITA versus free ITA:saline (scatter plot). C, Control ITA versus free ITA:Custodiol (scatter plot). D, Control ITA versus free ITA:Tiprotec (scatter plot). Fold change (2-DeltaCt) is the normalized gene expression (2-DeltaCt) in the test sample divided by the normalized gene expression (2-DeltaCt) in the control sample. The black line indicates fold changes ( 2 DeltaCt) of 1 . The pink lines indicate the desired fold change in gene expression threshold, defined by 2 . The red symbols identify upregulated genes, and the blue symbols downregulated genes. RNA from $\mathrm{n}=5$ pigs per group was isolated and the expression analyzed using polymerase chain reaction array from SA Biosciences (Qiagen, Hilden, Germany). SERPINE1, Plasminogen activator inhibitor-1; HIF1A, hypoxia-inducible factor 1-alpha; IL6, interleukin-6; $I C A M-1$, intercellular adhesion molecule-1; VCAM-1, vascular cell adhesion protein $1 ; I L B 1$, interleukin-1 beta; PRKCA, protein kinase C alpha; IL8, interleukin-8; VEGFA, vascular permeability factor; $T N F$, tumor necrosis factor alpha; $V W F$, Von Willebrand factor; GRIN2D, glutamate ionotropic receptor NMDA type subunit 2D; IL10, interleukin-10; $C I D E-B$, cell-death-inducing DNA-fragmentation-factor-like effector B; $M M P-9$, matrix metallopeptidase 9; $I L 7$, interleukin-7; C-JUN, proto-oncogen c-jun; BCL2, B-cell lymphoma 2; CAMK1, calcium-calmodulin-dependent protein kinase type 1; CASP3, caspase-3; $S O D 1$, superoxide dismutase; $B A X$, Bcl-2-like protein 4; NOS3, endothelial nitric oxide synthase.

the histidine-induced cytotoxicity, (3) addition of cardioprotective amino acids, and (4) increased potassium concentration. $^{12}$

In accordance with the previous results, we also showed a superior preservation capacity of Tiprotec over Custodiol and saline solutions. Furthermore, among the free ITA groups, the functional and structural impairment of the ITA graft was partly ameliorated by Tiprotec. An increased CD-31, eNOS staining, and reduced TUNEL-positive nuclei, ICAM-1 and VCAM-1 score, and nitro-oxidative 
stress were also detected in the Tiprotec group compared with the saline and Custodiol groups. Our findings also correlate to in vitro and in vivo studies, in which the detrimental effect of saline and Custodiol on the endothelium of grafts was reported. ${ }^{12,33}$

\section{CONCLUSIONS}

To the best of our knowledge, this is the first study that describes a high vulnerability of the ITA graft to reperfusion injury: the endothelial function and integrity of stored, free ITA grafts was largely abolished after reperfusion in daily used preservation solutions (saline, Custodiol). Among the free ITA groups, the vascular impairment of the ITA graft was partly ameliorated by the new preservation solution, Tiprotec. However, the endothelial cells of the in situ ITA graft showed no signs of IR injury. In conclusion, avoidance of daily used preservation solutions (saline/Custodiol) and preparation of the free arterial grafts similar to the in situ grafts should be considered.

\section{Limitations}

The off-pump model in this study was selected as a suitable model to evaluate in vivo IR injury. However, this model has certain limitations. Porcine ITA tissue differs from arterial grafts for CABG in the structure of the vessel wall, which limits the transferability of the results. Furthermore, direct correlation between graft patency and early vascular impairment was not investigated in our study. Even if upregulated MMP-9 and VEGF are indicative of $\mathrm{NIH}$ at later time points, we have no evidence at this point, so further studies are warranted. Furthermore, we have yet not tested free ITA grafts, which are prepared similarly to the in situ grafts, which are not subjected to storage.

\section{Conflict of Interest Statement}

Dr Szabó has a research grant from the Köhler Chemie $\mathrm{GmbH}$ (Bensheim, Germany) for another product (Custodiol). All other authors have nothing to disclose with regard to commercial support.

We thank Thomas Bruckner for his support with statistical analysis.

\section{References}

1. Locker C, Schaff HV, Daly RC, Dearani JA, Bell MR, Frye RL, et al. Multiple arterial grafts improve survival with coronary artery bypass graft surgery versus conventional coronary artery bypass grafting compared with percutaneous coronary interventions. J Thorac Cardiovasc Surg. 2016;152:369-79.e4.

2. Cameron A, Davis KB, Green G, Schaff HV. Coronary bypass surgery with internal-thoracic-artery grafts-effects on survival over a 15 -year period. N Engl J Med. 1996;334:216-9.

3. Nakajima T, Tachibana K, Takagi N, Ito T, Kawaharada N. Histomorphologic superiority of internal thoracic arteries over right gastroepiploic arteries for coronary bypass. J Thorac Cardiovasc Surg. 2016;151:1704-8.

4. Otsuka F, Yahagi K, Sakakura K, Virmani R. Why is the mammary artery so special and what protects it from atherosclerosis? Ann Cardiothorac Surg. 2013;2:519-26.
5. Sabik JF III, Olivares G, Raza S, Lytle BW, Houghtaling PL, Blackstone EH. Does grafting coronary arteries with only moderate stenosis affect long-term mortality? J Thorac Cardiovasc Surg. 2016;151:806-11.e3.

6. Attia T, Koch CG, Houghtaling PL, Blackstone EH, Sabik EM, Sabik JF III. Does a similar procedure result in similar survival for women and men undergoing isolated coronary artery bypass grafting? J Thorac Cardiovasc Surg. 2017;153:571-9.e9.

7. Taggart DP, D'Amico R, Altman DG. Effect of arterial revascularisation on survival: a systematic review of studies comparing bilateral and single internal mammary arteries. Lancet. 2001;358:870-5.

8. Magruder JT, Young A, Grimm JC, Conte JV, Shah AS, Mandal K, et al. Bilateral internal thoracic artery grafting: does graft configuration affect outcome? J Thorac Cardiovasc Surg. 2016;152:120-7.

9. Dion R, Glineur D, Derouck D, Verhelst R, Noirhomme P, El Khoury G, et al. Long-term clinical and angiographic follow-up of sequential internal thoracic artery grafting. $N$ Engl J Med. 2000;17:407-14.

10. Taggart DP, Altman DG, Gray AM, Lees B, Gerry S, Benedetto U, et al. Randomized trial of bilateral versus single internal-thoracic-artery grafts. N Engl J Med. 2016;375:2540-9.

11. Shi WY, Hayward PA, Tatoulis J, Rosalion A, Newcomb AE, Fuller JA, et al. Are all forms of total arterial revascularization equal? A comparison of single versus bilateral internal thoracic artery grafting strategies. J Thorac Cardiovasc Surg. 2015; 150:1526-33.

12. Veres G, Hegedus P, Barnucz E, Schmidt H, Radovits T, Zoller R, et al. TiProtec preserves endothelial function in a rat model. J Surg Res. 2016;200:346-55.

13. Azevedo LC, Pedro MA, Souza LC, de Souza HP, Janiszewski M, da Luz PL, et al. Oxidative stress as a signaling mechanism of the vascular response to injury: the redox hypothesis of restenosis. Cardiovasc Res. 2000; 47:436-45.

14. Liaudet L, Soriano FG, Szabo E, Virag L, Mabley JG, Salzman AL, et al. Protection against hemorrhagic shock in mice genetically deficient in poly (ADP-ribose)polymerase. Proc Natl Acad Sci U S A. 2000;97:10203-8.

15. Cordell JL, Falini B, Erber WN, Ghosh AK, Abdulaziz Z, MacDonald S, et al. Immunoenzymatic labeling of monoclonal antibodies using immune complexes of alkaline phosphatase and monoclonal anti-alkaline phosphatase (APAAP complexes). J Histochem Cytochem. 1984;32:219-29.

16. Veres G, Hegedus P, Barnucz E, Zoller R, Klein S, Schmidt H, et al. Endothelial dysfunction of bypass graft: direct comparison of in vitro and in vivo models of ischemia-reperfusion injury. PLoS One. 2015;10:e0124025.

17. Koch A, Bingold TM, Oberlander J, Sack FU, Otto HF, Hagl S, et al. Capillary endothelia and cardiomyocytes differ in vulnerability to ischemia/reperfusion during clinical heart transplantation. Eur J Cardiothorac Surg. 2001;20: 996-1001.

18. Veres G, Hegedus P, Barnucz E, Zoller R, Klein S, Radovits T, et al. Graft preservation with heparinized blood/saline solution induces severe graft dysfunction. Interact Cardiovasc Thorac Surg. 2015;20:594-600.

19. Lockerman ZS, Rose DM, Cunningham JN Jr, Lichstein E. Postoperative STsegment elevation in coronary artery bypass surgery. Chest. 1986;89:647-51.

20. Boyle EM Jr, Pohlman TH, Cornejo CJ, Verrier ED. Endothelial cell injury in cardiovascular surgery: ischemia-reperfusion. Ann Thorac Surg. 1996;62: 1868-75.

21. Szabo C. The pathophysiological role of peroxynitrite in shock, inflammation, and ischemia-reperfusion injury. Shock. 1996;6:79-88.

22. Pearce CG, Najjar SF, Kapadia MR, Murar J, Eng J, Lyle B, et al. Beneficial effect of a short-acting NO donor for the prevention of neointimal hyperplasia. Free Radic Biol Med. 2008;44:73-81.

23. Sellke FW, Boyle EM Jr, Verrier ED. Endothelial cell injury in cardiovascular surgery: the pathophysiology of vasomotor dysfunction. Ann Thorac Surg. 1996;62:1222-8.

24. Jaakkola K, Jalkanen S, Kaunismaki K, Vänttinen E, Saukko P, Alanen K, et al. Vascular adhesion protein-1, intercellular adhesion molecule-1 and P-selectin mediate leukocyte binding to ischemic heart in humans. J Am Coll Cardiol. 2000;36:122-9.

25. Boldt J, Kumle B, Papsdorf M, Hempelmann G. Are circulating adhesion molecules specifically changed in cardiac surgical patients? Ann Thorac Surg. 1998;65:608-14.

26. Diamond MS, Springer TA. A subpopulation of Mac-1 (CD11b/CD18) molecules mediates neutrophil adhesion to ICAM-1 and fibrinogen. J Cell Biol. 1993;120:545-56.

27. Bateman RM, Tkunaga C, Kareco T, Dorscheid DR, Walley KR Myocardial hypoxia-inducible HIF-1alpha, VEGF, and GLUT1 gene 
expression is associated with microvascular and ICAM-1 heterogeneity during endotoxemia. Am J Physiol Heart Circ Physiol. 2007;293: H448-56.

28. Yu PJ, Ferrari G, Pirelli L, Gulkarov I, Galloway AC, Mignatti P, et al. Vascular injury and modulation of MAPKs: a targeted approach to therapy of restenosis. Cell Signal. 2007;19:1359-71.

29. Hutter R, Carrick FE, Valdiviezo C, Wolinsky C, Rudge JS, Wiegand SJ, et al. Vascular endothelial growth factor regulates reendothelialization and neointima formation in a mouse model of arterial injury. Circulation. 2004;110:2430-5.

30. Guo L, Ning W, Tan Z, Gong Z, Li X. Mechanism of matrix metalloproteinase axis-induced neointimal growth. J Mol Cell Cardiol. 2014;66:116-25.

31. Karshovska E, Zernecke A, Sevilmis G, Millet A, Hristov M, Cohen CD, et al. Expression of HIF-1alpha in injured arteries controls SDF-1alpha mediated neointima formation in apolipoprotein E deficient mice. Arterioscler Thromb Vasc Biol. 2007;27:2540-7.

32. Beller CJ, Radovits T, Kosse J, Gero D, Szabo C, Szabo G. Activation of the peroxynitrite-poly(adenosine diphosphate-ribose) polymerase pathway during neointima proliferation: a new target to prevent restenosis after endarterectomy. J Vasc Surg. 2006;43:824-30.

33. Hoover EL, Ross M, Fani K, Webb H, Kirshy D, DiMaio F, et al. Biochemical and histopathologic comparison between blood and saline storage of canine veins. J Vasc Surg. 1988;7:543-8.

Key Words: internal thoracic artery, endothelial dysfunction, preservation solution, $\mathrm{CABG}$ 